\title{
Modifikasi Sistem ATS-AMF Diesel Emergency Generator Pada PLTU dengan Metode Warming Up
}

\author{
Hamzah Eteruddin ${ }^{1}$, David Setiawan ${ }^{2}$, Hebby Pradatama Sitepu ${ }^{3}$ \\ Program Studi Teknik Elektro, Fakultas Teknik, Universitas Lancang Kuning \\ Jl. Yos Sudarso Km. 8 Rumbai, Pekanbaru, Telp. (0761) 52324 \\ Email : hamzah@ unilak.ac.id ${ }^{1)}$,dsetia@ unilak.ac.id ${ }^{2}$, hebbysitepu@ gmail.com ${ }^{3)}$
}

\begin{abstract}
ABSTRAK
PLTU Tenayan Raya merupakan pembangkit termal berbahan bakar batubara yang berstatus baseload untuk menopang sistem kelistrikan di Riau khususnya Pekanbaru. Pengoperasian Diesel Emergency Generator (DEG) yang terkontrol merupakan cara utama agar peralatan-peralatan pendukung pada pembangkit listrik tidak berhenti beroperasi saat terjadinya kondisi emergency. Pada saat mengambil alih suplai tenaga listrik ke beban ataupun sebaliknya diperlukan Automatic Transfer Switch (ATS) - Automatic Main Failure (AMF) yang mempunyai peranan utama untuk memerintahkan DEG beroperasi. Agar DEG dapat bekerja dengan baik, diperlukan sistem ATS-AMF yang handal, dan dapat berkerja pada kondisi emergency maupun standby. Metode warming up dengan sensor-sensor yang digunakan dapat menjaga agar DEG senantiasa siap saat dibutuhkan.
\end{abstract}

Kata kunci : Thermal, baseload, ATS-AMF, Warming up, Diesel Emergency Generator

\begin{abstract}
PLTU Tenayan Raya is a coal base-load thermal generator that supports the electric system in Riau, especially Pekanbaru. The using controlled Diesel Emergency Generator (DEG) is the main method to prevent supporting devices of the power plant from an "out of order" situation in an emergency. As a controller to take the electrical power supply over the load or vice versa, Automatic Transfer Switch (ATS)-Automatic Main Failure (AMF) plays an important role to command DEG to operate. In order for DEG to work properly, a reliable ATS-AMF system is needed and can work in both emergency and standby conditions. The warming up method with the sensors used can keep DEG always ready when needed..
\end{abstract}

Keywords : Thermal, Baseload, ATS-AMF, Warming up, Engine, Emergency

\section{PENDAHULUAN}

Suplai energi dari pembangkitpembangkit besar perlu dijaga keberlangsungannya agar menjaga sistem tetap stabil. Telah banyak penelitian dilakukan untuk menjaga kestabilan pada system ketenagalistrikan [1]-[3]. Diesel Emergency Generator (DEG) dengan bantuan Automatic Transfer Switch (ATS)-Automatic Main Failure $(A M F)$ merupakan salah satu alat yang menjaga keberlangsungan suplai energi listrik dari Generator-generator besar. Guna menjaga peralihan sumber energi peralatan pendukung PLTU dari DEG ke energi yang berasal dari sistem (PLN) atau sebaliknya, digunakan. AMF akan memerintahkan DEG bekerja jika sumber energi yang berasal dari sistem (PLN) tiba-tiba terhenti. Guna memberikan perlindungan kepada pembangkit baik di unit mesin maupun generatornya.

Mengoperasikan panel ATS-AMF harus memperhatikan Keselamatan ketenagalistrikan terhindar dari kerusakan dan memperpanjang daya tahan [4], [5]. Pemeliharaan dilakukan antara lain Preventive, Corrective, Predictive, Running, Breakdown, Emergency, dan Shutdown Maintenance, Redesign [6]-[8].

Pembangkit Listrik Tenaga Uap (PLTU) sangat erat dengan tingginya tingkat polusi debu batubara [9], [10]. Jika tidak menggunakan panel dengan tingkat perlindungan yang baik, debu dapat mengotori kontak-kontak pada ATS. Kegagalan sistem ini berakibat DEG tidak dapat berfungsi. Untuk 
mengantisipasi hal ini diperlukan sebuah sistem kontrol otomatis. Banyak peneliti menggunakan mikrokontroler untuk menyelesaikan berbagai persoalan yang dihadapainya [11]-[13].

\section{METODE PENELITIAN}

Penelitian dilaksanakan pada PLTU Tenayan Raya, yang mengalami kegagalan sistem ATS-AMF akibat tebalnya debu yang menempel pada kontak-kontak dipanel. Hal ini berakibat system AMF gagal dalam mengirim signal untuk DEG bekerja. Adapun panel ATS sebagaimana terlihat pada Gambar 1.

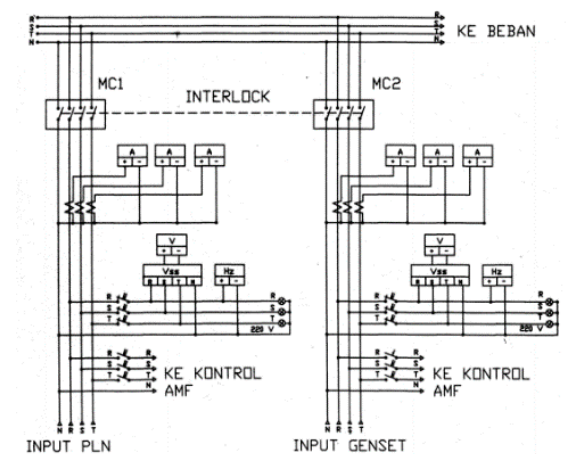

Gambar 1 Diagram ATS PLTU Tenayan Raya

Spesifikasi dari Diesel Emergency Generator dan Diesel Engine Generator yang terpasang adalah sebagaimana ditunjukkan pada Tabel 1 dan 2 .

Tabel 1 Spesifikasi Diesel Emergency Generator

\begin{tabular}{ll}
\hline Manufacture & Automatic Switch Co USA \\
Merk & ASCO \\
Serial Nomor & $1004795-001$ \\
S/O NO & 1337256 \\
Tegangan & 400 Volt \\
Phase & 3 \\
Rating & IE 800 \\
Frequency & $50 \mathrm{~Hz}$ \\
Wiring Diagram DWG & 617405 \\
Outline \& Mounting DWG & $725400-001-\mathrm{C}$ \\
Operator's Manual & $381333-339$ \\
Countrol Panel Guide & PN 381333-326 \\
BDM & 72782 \\
Cat No & H00300C3080J1X0 \\
\hline (Sumber data : PT. PJB UBJOM PLTU Tenayan Raya)
\end{tabular}

Pada saat itu, pengoperasian DEG masih dilakukan secara manual dan panel ATS yang digunakan tidak kedap terhadap debu. Untuk itulah Peneliti menggunakan metode warming up. Berfungsi sebagai pengendali otomatis dengan bantuan mikrokontroler (Arduino Uno) guna operasikan fan untuk memelihara kebersihan pada panel serta untuk pemanasan terjadwal tanpa harus mengganggu sistem.

Tabel 2 Spesifikasi Diesel Engine Generator

\begin{tabular}{ll}
\hline Model Diesel Engine Generator & QSX15-G8 \\
Engine No & 79739549 \\
Idle Speed & $700-900$ \\
Daya & $60 \mathrm{MVA}$ \\
Merk & Cummins \\
Fuel Rate & $449 \mathrm{~mm}^{3}$ \\
Standby Power & $670 \mathrm{HP} / 500 \mathrm{~kW}$ \\
Prime Power & $595 \mathrm{HP} / 444 \mathrm{~kW}$ \\
Limited Prime running Power & $595 \mathrm{HP} / 444 \mathrm{~kW}$ \\
Countinous Power & $425 \mathrm{HP} / 317 \mathrm{~kW}$ \\
Ref No & A0287496A \\
Displacement & 15 \\
CPL 8588 & 8588 \\
\hline (Sumber data : PT. PJB UBJOM PLTU Tenayan Raya)
\end{tabular}

\section{Spesifikasi Perancangan Alat}

Peralatan yang digunakan untuk simulasi pembuatan ATS dapat dilihat pada Tabel 3. Sementara Tabel 4 adalah alat untuk simulasi pembuatan Fan.

Tabel 3 Alat Untuk Simulasi Pembuatan ATS

\begin{tabular}{llcc}
\hline \multicolumn{1}{c}{ Nama Alat } & \multicolumn{1}{c}{ Type } & Jumlah & Satuan \\
\hline Relay & 5V DC & 5 & Unit \\
Arduino & Arduino Uno & 1 & Unit \\
Soket listrik & Kecil & 12 & Unit \\
Kabel Kecil & Serabut & 10 & Unit \\
Terminal listrik & AC/DC & 1 & Unit \\
Stop Kontak & AC/DC & 3 & Unit \\
Papan PCB & AC/DC & 1 & Unit \\
Adapter & 220V AC to $5 \mathrm{VDC}$ & 1 & Unit \\
Inverter & 300 Watt DC to $A C$ & 1 & Unit \\
Baterai & 12V DC & 1 & Unit \\
Lampu & $5 \mathrm{VDC}$ & 1 & Unit \\
\hline
\end{tabular}

Tabel 4 Alat Untuk Simulasi Pembuatan Fan

\begin{tabular}{cllcc}
\hline No & Nama Alat & \multicolumn{1}{c}{ Type } & Jumlah Satuan \\
\hline 1 & Kipas & 5VDC & 4 & Unit \\
2 & Arduino & Arduino Uno & 1 & Unit \\
3 & Sensor Debu & GP2Y1010AU0F & 1 & Unit \\
4 & Power Bank & Lion & 1 & Unit \\
5 & Kabel Kecil & Serabut & 12 & Unit \\
6 & Relay & $5 V D C$ & 1 & Unit \\
7 & Papan PCB & AC/DC & 1 & Unit \\
8 & Kapasitor & $1 \mu F($ mikro Farad $)$ & 1 & Unit \\
9 & Resistor & DC & 1 & Unit \\
\hline
\end{tabular}

Spesifikasi Komponen Yang Terhubung Pada Panel ATS-AMF.

1. Sensor debu yang digunakan adalah Sharp GP2Y1010AUOF dengan spesifikasi seperti pada Tabel 5.

Tabel 5 Nameplate Sensor Debu

\begin{tabular}{cll}
\hline No & \multicolumn{1}{c}{ Keterangan } & \multicolumn{1}{c}{ Value } \\
\hline 1 & Sampling Time & 280 microsecond \\
2 & Delta Time & 40 microsecond \\
3 & Sleeping Time & $9680 \mathrm{microsecond}$ \\
4 & Sensitivitas Sensor & $0,5 \mathrm{~V} / 0,1 \mathrm{mg} / \mathrm{m}^{3}$ \\
5 & Tegangan Input Sensor & $5 \mathrm{Volt}$
\end{tabular}


6 Rumus Sensor

DustDensity $=0.17$

$\mathrm{x}$ Voltage $-0,1$

(Sumber data : PT. PJB UBJOM PLTU Tenayan Raya)

2. Koneksi Arduino UNO dengan Sensor Debu digunakan untuk mengolah data. dari hasil pendeteksian sensor debu, data dikirimkan melalui Komunikasi Serial ke Pin Input Arduino Uno lalu apabila debu terbaca Arduino akan memerintahkan Fan untuk menghisap debu. Adapun koneksi Arduino UNO dengan Sensor Sharp GP2Y1010AUOF dapat dilihat pada tabel 6 :

Tabel 6 Sensor Debu Koneksi dengan Arduino uno

\begin{tabular}{cll}
\hline No & \multicolumn{1}{c}{ PIN } & \multicolumn{1}{c}{ Keterangan } \\
\hline 1 & Pin A4 & Output pin \\
2 & Pin A5 & Measure pin \\
3 & Pin 13 & Led power \\
4 & Pin 6 & LCD \\
5 & Pin 2 & LCD \\
\hline
\end{tabular}

Permasalahan Pada Diesel Emergency Generator (DEG)

Permasalahan yang terjadi pada Diesel Emergency Generator pada PLTU Tenayan Raya diambil dari data Logsheet Operasi dari bulan Juni 2016 - Desember 2017 berikut Tabel 7 kronologi gangguan berikut adalah data gangguan yang diambil dari logsheet operasi PLTU Tenayan Raya pada tahun 2016.

Tabel 7 Logsheet Data Gangguan Sistem Operasi

\begin{tabular}{ll}
\hline Waktu kejadian & Senin, 30 September 2016 \\
\hline Indikasi gangguan & Lepasnya PMT sisi Trafo SST \\
DEG & PLTU Tenayan Raya \\
Akibat gangguan & PLTU Tenayan trip, Diesel \\
& $\begin{array}{l}\text { Emergency Generator tidak } \\
\text { mau start }\end{array}$ \\
Indikasi & $\begin{array}{l}\text { DEG gagal start dikarenakan } \\
\text { gagalnya switch pada ATS } \\
\text { pindah }\end{array}$ \\
\hline
\end{tabular}

Pada perancangan alat untuk simulasi terbagi menjadi 2 bagian. Pertama yaitu program ATS berbasis warming-up, program untuk mengakusisi data dari pengkondisian sinyal tegangan, frekuensi yang ada pada sistem Automatic Transfer Switch (ATS) dan kedua program untuk perancangan otomatis pengoperasian fan yang terdapat pada box ATS.

\section{Perancangan Sistem ATS}

Rangkaian relay dan rangkaian pembaca tegangan menjadi sebuah sistem yang dapat berfungsi sebagai Automatic Transfer Switch
(ATS), seperti pada blok diagram sistem dari penggabungan tersebut seperti pada Gambar 2.

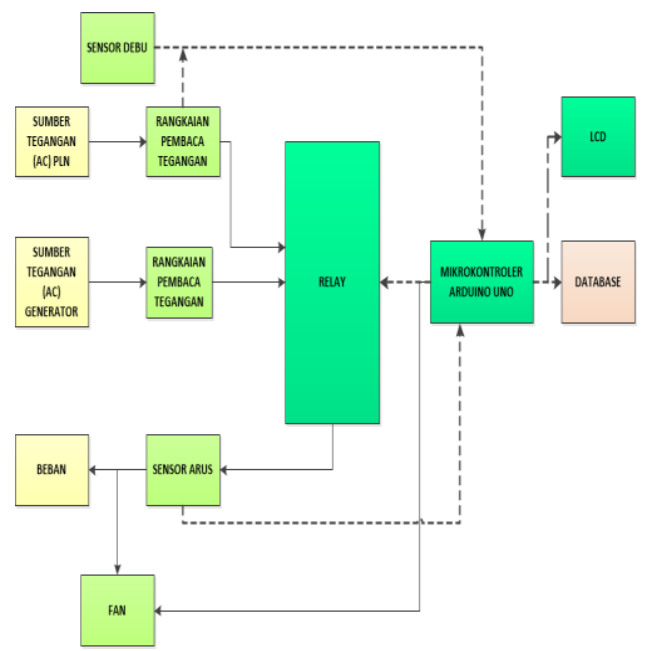

Gambar 2 Alur Kerja Mikrokontroler

Dalam Pembacaan Rangkaian tegangan ditempatkan diantara sumber tegangan dan relay, rangkaian pembaca tegangan ini, memiliki beberapa fungsi, diantaranya untuk menurunkan tegangan AC dari PLN dan sumber cadangan (generator set) dan juga berfungsi untuk menyesuaikan nilai arus dan tegangan dari sumber AC, sehingga nilainya dapat dibaca menggunakan proses Analog to Digital Converter (ADC) pada pin analog mikrokontroler dimana mikrokontroler yang dipergunakan yaitu Arduino UNO.

\section{Perancangan DEG Metode Warming $U P$}

Perancangan ini juga menggunakan relay 220 VAC dan Relay DC yang dihubungkan masuk ke Coil masing masing relay pada setiap phasanya $(\mathrm{R}, \mathrm{S}, \mathrm{T})$ berfungsi sebagai pengaman dan pembacaan. Seperti pada gambar 3 yang menunjukkan sebuah line Diagram perancangan Warming Up pada DEG.

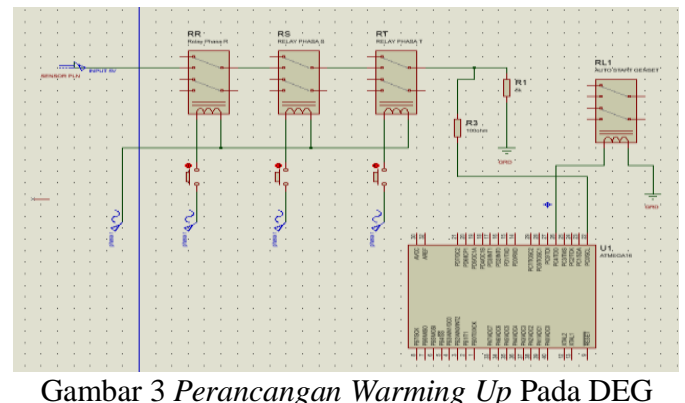

\section{Perancangan Pemrograman ATS}

Berikut scrip arduino/perintah pada pemograman yang di buat dalam bentuk scrip, 
agar program Arduino dapat berkerja change over switch ATS relay.

Keterangan Coding :

$$
\begin{array}{ll}
\text { int relayPLN }= & 10 \text { Merupakan pin untuk } \\
& \text { relay } \text { PLN } \\
\text { int relaybat } & 11 \text { Merupakan pin untuk } \\
& \text { relay Inverter/Bateraii } \\
\text { int relaygenset }= & 12 \text { Merupakan pin untuk } \\
& \text { relay genset } \\
\text { int relaystartergen }= & 13 \text { Merupakan pin sensor } \\
& \text { pembacaan tegangan } \\
& \text { genset } \\
\text { int sensor PLN }= & 2 \text { Sensor untuk PLN }
\end{array}
$$

Pengujian ATS Menggunakan Sumber PLN

Pengujian pada ATS bertujuan
mengetahui kehandalan perangkat yang sudah dibuat, diantaranya pengujian nilai tegangan keluaran AC regulator dengan tegangan yang terbaca pada LCD. Berikut uji coba 1 menggunakan tegangan $\mathrm{AC}$ sumber power PLN dapat dilihat pada Tabel 8.

\begin{tabular}{cccc}
\multicolumn{4}{c}{ Tabel 8 Nilai Error \% Dalam Pembacaan Tegangan } \\
\hline No & $\begin{array}{c}\text { Nilai Tegangan } \\
\text { Pada Multimeter }\end{array}$ & $\begin{array}{c}\text { Pembacaan } \\
\text { LCD }\end{array}$ & Error \\
\hline 1 & 180 Volt & - & - \\
2 & 190 Volt & - & - \\
3 & 200 Volt & 197 & $1,50 \%$ \\
4 & 210 Volt & 210 & $0,00 \%$ \\
5 & 220 Volt & 221 & $0,50 \%$ \\
6 & 229 Volt & 231 & $0,90 \%$ \\
\multicolumn{4}{c}{ Error rata-rata } \\
\hline
\end{tabular}

Relai tegangan yang ada pada DEG berfungsi sebagai sensor pembaca, relai diset bekerja pada 2 pengaturan tegangan standar 220 Volt $+5 \%$ dan $-10 \%$ sesuai standar PUIL 2000.

1. Relai bekerja pada tegangan minimum 198 Volt

2. Relai bekerja pada tegangan maksimum 231 Volt.

Dengan demikian apabila tegangan pada sumber utama jatuh pada tegangan minuman dengan otomatis arduino akan memerintahkan ATS untuk change over switch ke DEG. Pada pengujian diatas dapat kita lihat relai tegangan bekerja dengan error rata-rata sebesar 0,7\% Pengujian dapat dilihat pada Gambar 4.

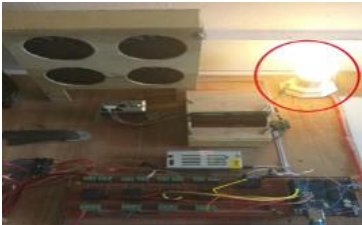

Gambar 4 Pengujian ATS Pada Sumber PLN

Pengujian ATS Menggunakan Sumber DEG

Pengujian pada sensor tegangan DEG hampir sama dengan pengujian sensor tegangan PLN. Pengujian ini menggunakan tegangan AC regulator. Pengujian ATS sumber DEG dengan pembacaan LCD dapat dilihat pada tabel 9.

Tabel 9 Pengujian ATS Sumber DEG

\begin{tabular}{cccc}
\hline No & $\begin{array}{c}\text { Nilai Tegangan Pada } \\
\text { Multimeter }\end{array}$ & $\begin{array}{c}\text { Pembacaan } \\
\text { LCD }\end{array}$ & Error \\
\hline 1 & 180 Volt & - & - \\
2 & 190 Volt & - & - \\
3 & 200 Volt & 197 & $1,50 \%$ \\
4 & 210 Volt & 210 & $0,00 \%$ \\
5 & 220 Volt & 221 & $0,50 \%$ \\
6 & 230 Volt & 232 & $0,90 \%$ \\
7 & 240 Volt & - & - \\
& Error rata-rata & & $\mathbf{0 , 7 0 \%}$ \\
\hline
\end{tabular}

Berdasarkan hasil pengujian pada Tabel 9 dapat diambil kesimpulan bahwa sensor tegangan pada DEG akan bekerja pada tegangan minimum 197 Volt dan tegangan maksimum 232 Volt dan nilai tegangan ditampikan pada LCD ATS dengan penyipangan rata-rata volt meter $0,7 \%$ dimana pada kondisi tersebut Arduino memerintahkan DEG manuver kembali kesumber PLN saat tegangan kembali normal. Pengujian dapat dilihat seperti pada Gambar 5.

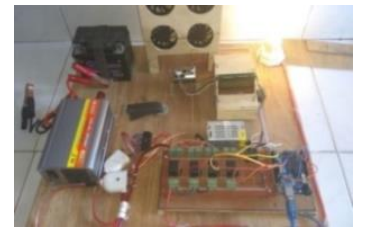

Gambar 5 Pengujian Relai Sumber DEG
Pengujian
ATS Menggunakan Relai
Frekuensi
Pengujian ini dilakukan dengan cara mengukur frekuensi yang dibangkitkan generator function dan membandingkan hasil pengukuran yang ditampilkan pada LCD ATS. Amplitudo generator function yang di set 4.5 Volt. Pengujian Sensor Frekuensi dapat dilihat pada Tabel 10

Tabel 10 Sensor Frekuensi Pada ATS 


\begin{tabular}{cccc}
\hline No & Frekuenzi (Hz) & ATS (Hz) & Error (\%) \\
\hline 1 & 40 & 41 & $2,40 \%$ \\
2 & 45 & 46 & $2,20 \%$ \\
3 & 50 & 51 & $2,00 \%$ \\
4 & 55 & 56 & $1,80 \%$ \\
5 & 60 & 61 & $1,60 \%$ \\
& Error rata-rata & & $2,00 \%$ \\
\hline
\end{tabular}

Berdasarkan Tabel 10 pengujian diatas dapat diambil kesimpulan bahwa pengukuran dengan frekuensi yang berbeda-beda nilai error terbesarnya adalah $2.4 \%$, dan rata-rata hasil pengujian keseluruhan nilai error adalah $2.0 \%$ Pengujian Pemilihan Sistem Tenaga

Pengujian ini bertujuan untuk menguji prioritas sistem tenaga yang akan dipakai dan akan disalurkan kebeban saat semua parameter sumber sistem tenaga terpenuhi. Hasil Pengujian dapan dilihat pada Tabel 11.

\begin{tabular}{ccccc}
\multicolumn{5}{c}{ Tabel 11 Pengujian Sistem Tenaga } \\
\hline \multirow{2}{*}{ No } & PLN & DEG & Baterai & Keterangan \\
\hline 1 & 1 & 1 & 1 & PLN \\
2 & 1 & 1 & 0 & PLN \\
3 & 1 & 0 & 0 & PLN \\
4 & 1 & 0 & 1 & PLN \\
5 & 0 & 0 & 1 & Batere \\
6 & 0 & 1 & 0 & DEG \\
7 & 0 & 1 & 1 & DEG \\
8 & 0 & 0 & 0 & - \\
\hline
\end{tabular}

Keterangan :

$$
\begin{array}{ll}
0 & =\text { Tidak Ada } \\
1 & =\text { Ada }
\end{array}
$$

\section{Pengujian Beban}

Pengujian ini bertujuan untuk mendapatkan data kondisi yang dialami peralatan listrik yang uji saat terjadi proses manuver sistem tenaga. Beberapa peralatan listrik yang digunakan pada pengujian prototype ini dapat dilihat pada Tabel 12 .

Tabel 12 Pengujian Prototype Saat Berbeban

\begin{tabular}{|c|l|c|c|c|}
\hline No & Jenis Beban & $\begin{array}{c}\text { Daya } \\
\text { Watt }\end{array}$ & Jumlah & Status Beban \\
\hline 1 & Lampu Pijar & 10 & 1 buah & Tidak Berkedip \\
\hline 2 & Lampu Pijar & 100 & 1 buah & Tidak Berkedip \\
\hline 3 & Dispenser & 250 & 1 buah & Bekerja Normal \\
\hline 4 & Setrika & 350 & 1 buah & Bekerja Normal \\
\hline 5 & Infokus & 350 & 1 buah & Bekerja Normal \\
\hline
\end{tabular}

Pengujian beban pada keluaran semua peralatan yang diuji seperti pada Tabel 12 dengan adanya transfer time masih dapat beroperasi secara normal. Hal tersebut terjadi karena rangkaian penyearah pada peralatan yang di uji terdapat kapasitor yang cukup besar. Kapasitor pada rangkaian penyearah masih dapat membackup beban selama waktu yang ditunjukan pada Tabel 12 Transfer Time pada perancangan ini ditentukan oleh bagianbagian penyusun prototype. Baik dari segi hardware, maupun dari segi software.

\section{Pengujian Pada Gangguan}

Parameter pengenal PLN adalah frekuensi dan tegangan, parameter pengenal DEG adalah tegangan. Pengujian dilakukan dengan cara memberikan gangguan pada parameter pengenal sistem tenaga. Gangguan berupa frekuensi tinggi/rendah digunakan inverter yang telah didesain untuk diubah frekuensinya seperti Tabel 13

Tabel 13 Pengujian Saat Mengalami Gangguan

\begin{tabular}{|c|c|c|c|c|}
\hline \multicolumn{3}{|c|}{ Sumber Tenaga (Volt) } & \multirow{2}{*}{ Sumber Beban } & \multirow{2}{*}{ Kondisi DEG } \\
\cline { 1 - 3 } Volt PLN & Volt DEG & Frekuensi & & \\
\hline 170 & 160 & 55 & UPS & Delai 5 detik \\
\hline 250 & 222 & 48 & DEG & Menyala \\
\hline 145 & 98 & 60 & UPS & DEG dimatikan \\
\hline 187 & 220 & 65 & DEG & Menyala \\
\hline
\end{tabular}

Pada pengujian gangguan kombinasi, ATS berhasil melakukan manuver. Dengan pengujian sebagai berikut. Beban disuplai dari UPS, kondisi tegangan PLN rendah, frekuensi PLN tinggi serta tegangan DEG rendah. Pada kodisi tegangan DEG rendah ATS melakukan manuver tunda selama 5 detik. Ketika tegangan telah terpenuhi beban disuplai dari DEG. Jika tidak genset dimatikan otomatis. Beban disuplai dari genset ketika tegangan PLN tinggi, frekuensi PLN rendah. Beban disuplai dari UPS saat tegangan PLN rendah, frekuensi PLN tinggi dan tegangan genset juga tinggi. Beban disuplai dari genset saat tegangan PLN rendah dan frekuensi PLN rendah seperti pada Gambar 6.

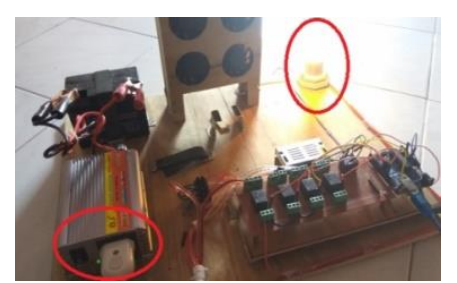

Gambar 6 Pengujian Gangguan Beban Disuplai Dari Genset Saat Tegangan PLN rendah dan Frekuensi PLN rendah

\section{Perancangan Sensor Debu}

Perancangan sensor debu digunakan untuk memproteksi debu yang masuk berlebih pada box panel ATS-AMF. Pada panel ATS- 
AMF akan diberi sensor debu GP2Y1010AU0F, jika sensor debu membaca adanya debu maka sensor tersebut mengirimkan sinyal ke mikrokontroler, lalu mikrokontroler memerintahkan fan beroperasi untuk menyedot debu, seperti pada rancangan Gambar 7

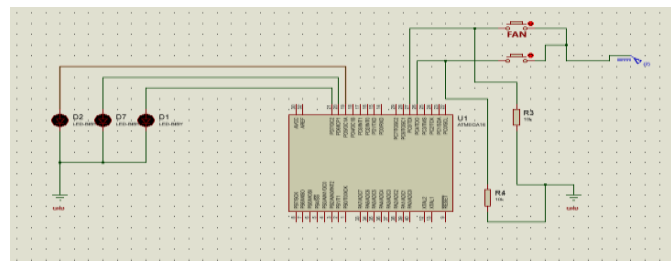

Gambar 7 Perancangaan Sensor Debu

\section{Perancangan Pemrograman Pada Sensor} Debu

Berikut scrip pemograman pada sebuah arduino/perintah, pemrograman yang di buat dalam bentuk scrip untuk agar mikrokontroler memerintahkan sensor debu berkerja.

Keterangan pada Script Arduino :

int measurePin $=$ A5 Merupakan pin pada power utama

int ledPower =13 Merupakan sinyal lampu output

int samplingTime $=280$ Perubahan data yang di tampilan di monitor LCD

int deltaTime $=40$ Perubahan data yang di rasakan oleh relay.

int sleepTime $=9680$ waktu delay

float voMeasured $=0$

float calcVoltage $=0$ Perubahan tegangan pada layar LCD

float dustDensity $=0$ Sensitivitas debu

\#include <LiquidCrystal.h>

LiquidCrystal $\operatorname{lcd}(12,11,5,4,3,2)$;

int measurePin $=\mathrm{A} 5$;

int ledPower $=13$;

int sampling Time $=280$;

int deltaTime $=40$;

int sleepTime $=9680$

float voMeasured $=0$

float calcVoltage $=0$;

float dustDensity $=0$

void $\operatorname{setup}()\{$

Serial.begin(9600);

pinMode(measurePin, INPUT);

pinMode(ledPower,OUTPUT);

pinMode(A3, OUTPUT);

void $\operatorname{loop}()\{$

lcd.begin $(16,2)$;

digitalWrite(ledPower,LOW);

delayMicroseconds(samplingTime);

voMeasured $=$ analogRead $(\operatorname{measurePin})$;

delayMicroseconds(deltaTime);

digitalWrite(ledPower,HIGH);

delayMicroseconds(sleepTime);
calcVoltage $=$ voMeasured $*(3.3 / 1024)$

dustDensity $=(0.17 *$ calcVoltage $)-0.1$;

lcd.print("RSV(0-1023):"); //Raw Signal Value

(0-1023)

lcd.print(voMeasured);

lcd.print(" V:"); //Voltage

lcd.print(calcVoltage);

lcd.print(",DD:"); //Dust Density

lcd.println(dustDensity);

delay(1000);

if (dustDensity > 0.1)

digitalWrite( A3, HIGH);

delay(100);

\}

else \{

digitalWrite(A3,LOW);

delay $(100) ;\}$

\section{Pengujian Sensor Debu}

Pengujian dilakukan pada sensor debu untuk menunjukkan bahwa sensor dapat bekerja membaca debu dan memberikan sinyal kepada arduino, selanjutnya arduino memerintahkan fan berkerja menghisap debu seperti pada Gambar 8 wiring sistem kerja sensor debu.

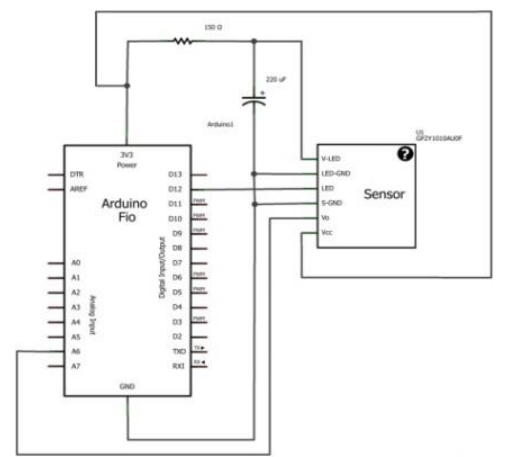

Gambar 8 Wiring Sistem Kerja Sensor Debu

Pada Gambar 8 percobaan disini sensor debu diberikan input 5 VDC untuk memberikan indikasi lampu sensor debu menyala,sumber tegangan yang dibaca oleh sensor tadi di teruskan ke arduino, selanjutnya arduino memerintahkan fan berputar untuk menghisap debu seperti pada Gambar 9

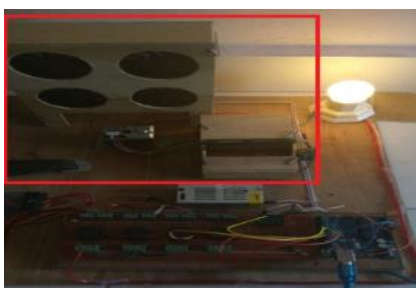

Gambar 9 Arduino Memerintahkan Fan Berputar

Selanjutnya uji coba untuk menentukan jumlah kipas fan in dan out meliputi 3 macam percobaan, sampai ditemukan hasil yang 
memuaskan. Karakteristik sensor debu Sharp GP2Y1010AU0F adalah mampu mendeteksi debu yang sangat halus dan juga asap. Pada proses uji coba, ukuran debu harus memiliki ukuran yang tetap pada setiap percobaan. Sehingga, pada uji coba ini peneliti menggunakan koran yang dibakar, pemilihan menggunakan koran yang dibakar adalah selain menghasilkan partikel kertas yang terbakar, juga menghasilkan asap. Jumlah koran yang dibakar setiap uji coba adalah 2 lembar. Sebagai pembanding, dipilih bedak bayi sebagai ujicoba karena partikelnya kecil dan beratnya dapat diukur. Bedak bayi diukur 10 mg menggunakan timbangan neraca, kemudian diletakkan di dalam kotak sebelum kotak pendeteksi debu diaktifkan. Berikut Tabel 14 Pengujian 1 fan (uji coba 1).

Tabel 14 Bahan Uji Terhadap Reaksi Sensor Debu

\begin{tabular}{clccc}
\hline No Jenis Bahan & $\begin{array}{c}\text { Waktu } \\
\text { Deteksi } \\
(\text { detik) }\end{array}$ & $\begin{array}{c}\text { Waktu } \\
\text { Cleaning } \\
(\text { detik })\end{array}$ & $\begin{array}{c}\text { Kepadatan } \\
\text { Debu } \\
\left(\mathrm{mg} / \mathrm{m}^{3}\right)\end{array}$ \\
\hline 1 & $\begin{array}{l}\text { Koran yang } \\
\text { dibakar }\end{array}$ & 1 & 16 & 0,28 \\
2 & \begin{tabular}{l} 
Bedak \\
\hline
\end{tabular} & 3 & 20 & 0,28 \\
\hline
\end{tabular}

Berdasarkan Tabel 14 diatas, dapat diketahui bahwa pada uji coba ke-1 waktu sensor untuk dapat mendeteksi debu koran yang dibakar adalah 1 detik, dengan waktu cleaning 16 detik dan Kepadatan debu/asap $0,28 \mathrm{mg} / \mathrm{m}^{3}$. Sedangkan untuk bedak dapat dideteksi dalam waktu 3 detik dengan waktu cleaning 20 detik dan kepadatan debu 0,36 $\mathrm{mg} / \mathrm{m}^{3}$.

\section{KESIMPULAN}

Berdasarkan penelitian yang dilakukan diperoleh kesimpulan sebagai berikut :

1. Prototype dapat bekerja dengan baik, ketika tegangan suplai utama minimum sebesar 189 VAC dengan frekuensi minimum 48 $\mathrm{Hz}$.

2. Penggunaan sensor debu GP2Y1010AUOF dapat diandalkan untuk mendeteksi jumlah debu yang ada, sehingga sistem yang dibuat dapat mengatur waktu (lama) fan bekerja membersihkan panel guna menghindari penumpukan debu.

\section{DAFTAR PUSTAKA}

[1] H. Hendry, H. Eteruddin, and A. Atmam, "Analysis of Voltage Sag Due to Short Circuit on the Sub System in Central Sumatera," Int. J. Electr. Energy Power Syst. Eng., vol. 1, no. 2, pp. 1-5, 2018.

[2] R. K. Sinha, R. Kumar, M. Venmathi, and L. Ramesh, "Analysis of Voltage Sag with Different DG for Various Faulty Conditions," Int. J. Comput. Commun. Inf. Syst., vol. 2, no. 1, pp. 189-193, 2010 .

[3] B. Sebastian and R. Garg, "Transient stability analysis of multi-machine power system and first swing stability analysis using SVC," in 2014 International Conference on Advances in Electrical Engineering (ICAEE), 2014, pp. 1-4.

[4] J. Shodiq, "Perawatan dan Pemeliharaan Panel ATS-AMF," Politeknik Negeri Semarang, 2014.

[5] “Tips Seputar Panel ATS/AMF," $P T$. Prima Market Jaya Abadi, 2012. [Online]. Available: http://www.primamarket.com/tips-seputar-panel-atsamf/. [Accessed: 01-Apr-2020].

[6] U. PLTU Tenayan Raya, Buku Saku Pedoman Pemeliharaan. Pekanbaru: PT. Pembangkitan Jawa Bali, 2016.

[7] K. Mobley, L. Higgins, and D. Wikoff, Maintenance Engineering Handbook, 7th ed. New York: McGraw-Hill Education, 2008.

[8] M. Ben-Daya, S. O. Duffuaa, A. Raouf, J. Knezevic, and D. Ait-Kadi, Handbook of Maintenance Management and Engineering. London: Springer London, 2009.

[9] P. Breeze, Coal-Fired Generation. London: Elsevier Science, 2015.

[10] J. G. Speight, Coal-Fired Power Generation Handbook. New Jersey: Wiley, 2013.

[11] D. Setiawan, H. Eteruddin, and M. Idris, "Analisis Pengaruh Perubahan Tegangan Terhadap Iluminasi Lampu Menggunakan Raspberry-Pi di Universitas Lancang Kuning," J. Tek., vol. 13, no. 1, pp. 1724, 2019.

[12] R. Jefysa, H. Eteruddin, and D. Setiawan, 
“Otomasi Pemakaian Energi Listrik Pada Ruangan Perkuliahan Akademi Komunitas Negeri Pelalawan Menggunakan Fuzzy Logic Berbasis Mikrokontroler," in Seminar Nasional Cendekiawan, 2019, pp. 1-11.
[13] D. Setiawan, H. Eteruddin, and A. Arlenny, "Desain dan Analisis Inverter Satu Fasa Berbasis Arduino Menggunakan Metode SPWM," J. Tek., vol. 13, no. 2, pp. 128-135, 2019. 